\title{
THE INFLUENCE OF PHONEMIC AWARENESS INSTRUCTION ON EFL EMERGENT READERS' WORD RECOGNITION
}

\author{
Mohammad Husam Alhumsi \\ Saudi Electronic University, Riyadh, Saudi Arabia \\ E-mail:m.alhumsi@seu.edu.sa
}

Received: 04 November 2019

Accepted: 13 December 2019

\begin{abstract}
Research has considered phonemic awareness skill as effective pillar in acquiring literacy skills. This skill has been identified as prerequisite for reading success However, little is known about the phonemic awareness instruction of Jordanian EFL emergent readers. This study therefore explored the impact of phonemic awareness instruction on word recognition among Jordanian EFL emergent readers. In this study, the research instrument was semi-structured interviews. Seven EFL students of emergent readers were interviewed. They were all first graders aged 7 years on average. Data were analyzed using content analysis. The findings indicated that there is a lack of knowledge or misunderstanding between the term of phonics and phonemic awareness as well. It has been also found that emergent readers' views show positive support towards the use of phonemic awareness skill. At the end of the study, some pedagogical implications for curriculum designers as well as English teachers were provided accordingly.
\end{abstract}

Keywords: Phonemic Awareness, Phonemic Awareness Instruction, EFL Emergent Readers, Word recognition, Jordan

\section{Introduction}

Reading is a pivotal skill that affects young learner's educational aspect in life. Recent research confirmed that developing strong reading skills forms an important cornerstone in the life of young learners in their beginning years of schools (Kern \& Friedman, 2008; Kucukoglu, 2013; Suggate, Schaughency, \& Reese, 2013). Research also affirmed that reading leads to noticeable academic outcomes (Senechal \& LeFevre, 2002; Kern \& Friedman, 2008). Thus, reading can be defined as a complicated system of skills and knowledge in which all components of that system function together and improve one another (Senechal \& LeFevre, 2002; Adams, 1994). In USA, studies have revealed that this complicated system requires certain pillars such as phonemic awareness, word recognition, background knowledge, fluency, comprehension strategies, and a motivation to read (Snow, Burns \& Griffin, 1998; International Reading Association, 1999).

The Phonemic awareness, considered as one important pillar, refers to the ability to hear and manipulate the sounds in words and the ability to understand that these oral words and their syllables consist of a series of sounds (Yopp, 1992). Phonemic awareness falls under the umbrella of phonological awareness. Phonological awareness is a component of metalinguistic awareness which is the process of thinking about one's own language (Yopp \& Yopp, 2000). It involves segmenting spoken words into phonemes (Chapman, 2003). 
Regarding word recognition, it can be defined as words that are automatically and immediately recognized as a whole by emergent readers and the analysis for their identification is not required (Ehri, 2014; Ehri, 2005).

It has been also found that Phonemic awareness has been characterized as one of the important skills in learning to read and write (Walsh, 2009). In addition, it is significant to note that the issue of phonemic awareness skills, particularly segmenting and blending, in pre-literacy and early literacy development is critical in the early literacy literature (Anthony \& Lonigan, 2004; Nation \& Hulme, 1997; Yeh, 2003). However, research stressed that a broad gap between research knowledge state concerning learning to read and public understanding condition still exists (Castles, Rastle, \& Nation, 2018). This means that a poor reader will find difficulty in understanding English skills, particularly reading. He/she also will struggle and face difficulties through every school day while practicing reading skill. This may force him/her to drop out and lose potential education opportunities and this only creates poverty among generation (Gove \& Cvelich, 2010). Thus, Jordanian children must have the ability to be proficient in the basic reading skill of English language.

However, less is known about the phonemic awareness instruction of Jordanian EFL emergent readers (Alhumsi \& Affendi, 2014; Alhumsi \& Affendi, 2016) Thus, this study aims at exploring the impact of the phonemic awareness skill on word recognition among Jordanian emergent readers.

The significance of this study stems from the fact that there is a remarkable need in Jordanian educational system to shed the light on students who are at-risk in reading skill. Early intervention is a rigorous program for all students, particularly for those who struggle with reading. For instance, Torgesen et al. (2001) confirmed that students who have difficulties in reading skills often experience difficulties in the area of phonemic analysis skills. They added that students are required to have an intensive and systematic program in order to remedy the difficulties in reading. Moreover, it should be noted that curriculum designers, principals, and English teachers should depend on the findings of the research to guide instructional and firm decisions to accelerate the development of reading skill process. Consequently, few studies have been identified to address the phonemic awareness skill among Jordanian EFL beginning readers concerning the use of phonemic segmentation skill.

\section{Literature Review}

It is evident that reading is essential for academic success as learners acquire new knowledge that provides foundational links required for lifelong reading success. It is also crucial for life and it is a "foundation skill for school learning and life learning" (Lane, Pullen, Eisele, \& Jordan, 2002, p. 101). A number of scholars regarded reading as a linguistic skill which depends on the combination of adequate language abilities in phonological, semantic, syntactic and pragmatic areas (Archibald \& Gathercole, 2007; Fender, 2003; Lonigan, Schatschneider, \& Westberg, 2008; Adams, 1994). Some researchers considered reading as a skill based on high level of complicated cognitive processing (Dehaene \& Naccache, 2001; Baddeley, 2007). Others defined reading skill as the identification of printed words (Perfetti \&Marron (1998).

Furthermore, the International Reading Association of America $(1999,2014)$ and Adams (1994) defined reading as a complex system made up of deriving meaning from print and this system needs the incorporation of the following items: the developing process and perpetuation of a motivation to read, the developing process of relevant efficient strategies to build meaning from print, building sufficient background information and vocabulary to 
encourage reading comprehension, learners' ability to decode unknown words, learners' ability to read fluently, and finally learners' skills and knowledge in order to comprehend the way phonemes or speech sounds are associated to print (International Reading Association, 1999, 2014). However, the US National Reading Panel's report emphasizes five elements of reading instruction regarding reading skill. These elements involve phonics, phonemic awareness, vocabulary, comprehension, and fluency (National Reading Panel, 2000; Nag, Chiat, Torgerson, \& Snowling, 2014).

Phonemic awareness is an essential precursor to reading skill and fluent decoding (Whitehurst \& Lonigan, 1998; Anthony, Williams, McDonald, \& Francis, 2007). Yopp (1992) provided a definition to Phonemic awareness. She stated that this skill involves learners' ability to hear and manipulate the sounds in words. It also involves learners' ability to recognize that oral words and their syllables contained a series of sounds. It should be noted that phonemic awareness lies under the category of phonological awareness. According to Yopp \& Yopp (2000), phonological awareness is a component of metalinguistic awareness, meaning that it is the process of thinking about one's own language. This particular skill includes segmenting spoken words into discrete sounds (Chapman, 2003).

For example, the phonemic segmentation skill, one of phonemic awareness skills, is essential in the critical stages of early literacy due to its association with future reading success (National Reading Panel, 2000; Schuele \& Boudreau, 2008; Vaughn \& LinanThompson, 2004). It is regarded as one of several skills of phonemic awareness in which beginning readers can segment words into individual phonemes. For example, "What are the sounds in bag?" (Ehri et al., 2001).

However, the phonemic segmentation skill is considered as the most difficult skills of phonemic awareness (Yopp \& Yopp, 2009; Griffith \& Olson, 1992; Adams, 1994). It is crucial to indicate that this skill has a strong correlation concerning learning to read and word recognition (Stanovich, 1986; Adams, 1994). In addition, it forms a critical bridge that results in the development of word recognition (Alhumsi \& Affendi, 2016).

To clarify how the skill of phonemic segmentation functions, Griffith and Olson (1992), Adams (1994) and Manning (2005) affirmed that phoneme segmentation is demonstrated when a teacher provides his/her students with a word and ask them to try to orally break the word apart into its smallest components. Featuring as progressive process, Manning (2005) proposed that phoneme segmentation skill should be clarified in four different levels. The first level includes no segmentation of the word and the student just repeats the word being heard. As for the second level, the students need to divide the word by syllables. The third level deals with the separation of the syllables into segments. The last level is accomplished when a student divides all the phonemes in the word (see Table 1). Thus, in order to assist teachers to enhance the development and success of each single learner when practicing segmentation skill, they should be able to recognize the definite progressive level in which a student is segmenting words into phonemes.

Table 1

The Four Different Levels of Segmenting the Word "pony"

\begin{tabular}{lll}
\hline Progressive Level & Student Reaction & Demonstration \\
\hline Level 1 & /pony/ & There is no segmentation of the word \\
Level 2 & $/ \mathrm{po} /-/ \mathrm{ny}$ & Words are divided by syllables \\
Level 3 & $/ \mathrm{p} /-/ \mathrm{o} /-/ \mathrm{ny} /$ or /po/-/n/- & $\begin{array}{l}\text { Students separated one syllable into } \\
\text { segments }\end{array}$
\end{tabular}


The Influence of Phonemic Awareness Instruction on EFL Emergent Readers' Word Recognition, Mohammad Husam Alhumsi

Level 4 /p/-/o/-/n/-/y/

Students segmented all phonemes

(Adapted from Manning, 2005)

As for the tasks of phonemic segmentation, they have also been found to be an effective component of phonological awareness program (Chiappe, Siegal, \& Wad-Wooley, 2002; Chard \& Dickson, 1999; Good, Simmons \& Smith, 1998). The instruction of phonemic segmentation requires children to break down words into their constituent sounds (Tunmer \& Nesdale, 1985; Yopp \& Yopp, 2000; Adams, 1994). Research showed that phonemic segmentation skill facilitates the reading process (Adams, 1994; National reading Panel, 2000; Yeh \& Connell, 2008) and it has increased more success in word recognition (Ball \& Blachman, 1991; Kim, Kim, \& Lee, 2007; Al Otaiba, Kosanovich-Grek, \& Torgesen, 2012) and reading comprehension (Yeh \& Connell, 2008).

In Jordan, emergent readers may not experience a full-blown sense of English phonemic awareness at the time of registration at school (Al-Shaboul, Assasfeh, Alshboul, \& Almomani, 2013). Luckily, it is interesting to note that phonemic segmentation skill can be gained within duration of time (Reading \& Van Deuren, 2007). It also helps students reveal the obscurity causing them to struggle with reading in the early reading stages. In other words, reading ability may explicitly develop through the assistance of the instruction of phonemic awareness skills that leads to recognizing words.

Westwood (2001) pointed out that the word recognition process occurs when the students have the ability to get back a word from memory, decode the letters and combine the phonemes to make the intended word. Moreover, word recognition skill includes recognizing what a word means and sounding it out. Vaughn and Linan-Thompson (2004) confirmed that sounding out words encompasses the idea that students are able to convert the printed words into speech sounds since speech is significant in expressing and reflecting ideas, emotions, and thoughts (Ganie, Maulana, \& Rangkuti, 2019).

It is interesting to indicate that the definite component of the reading processes is word recognition. Literature affirmed that "Recognition of the fact that words are composed of sounds is important for the following step within the period of early literacy, namely learning to identify words" (Aarnoutse, Van Leeuwe, \& Verhoeven, 2005, p. 254). Thus, focusing on the phoneme, which is the smallest unit of sound, enables students to have an opportunity to link a sound with its letter representation (Alhumsi \& Shabdin, 2016). In this way, learners can recognize the connection between sounds and letters by having understood the alphabetic code of the English language in order that they can start developing such connection. Shankweiler and Fowler (2004, p. 487) confirmed that "the phoneme is the most critical segment for grasping the alphabetic principle and learning to use it". Hence, each letter is distinguished by a certain sound that helps students identify the words introduced. These words should be decoded as well. It has been found in literature that the process of learning to read encompasses representing letters to their individual phonemes (Gray \& McCutchen, 2006; Foy \& Mann, 2006; Alhumsi \& Affendi, 2016).

Moreover, it is important to note that Ehri (2005) offered developmental phases of word recognition. These phases form the theoretical framework to this paper. Ehri (2005) identified and studied four phases of development with respect to fully automatic sight word reading. These involve pre-alphabetic, partial alphabetic, full alphabetic and consolidated alphabetic. The same researcher strongly argued that these are not considered stages that need to be learned sequentially. On the other hand, she called them phases in which these phases simply address the remarkable types of alphabetic knowledge. 
This paper focuses on Ehri's model (2005) of word recognition phases. Ehri (2005) affirmed that certain prerequisite literacy knowledge is significant for children to form complete connections. The phases of word recognition development presented by Ehri (2005) are most readily applicable to decoding, or the process of sounding out and blending graphemes into phonemes.

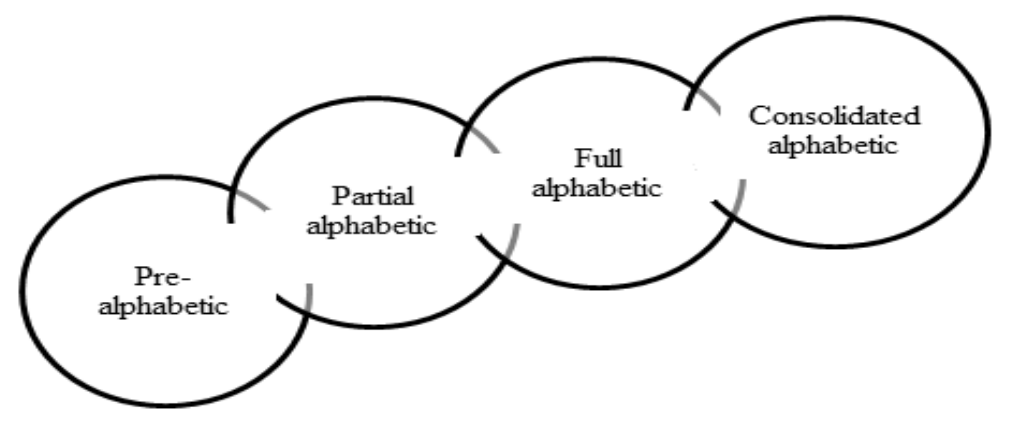

Figure 2. An illustration of Ehri's (2005) phases of word recognition development. (Adopted from Beech (2005))

This theoretical framework suggested by Ehri (2005) offers four phases. These phases are as follows: pre-alphabetic, partial alphabetic, full alphabetic, and consolidated alphabetic phases. During the pre-alphabetic phase, children rely mainly on environmental cue to read words because they have little understanding that the letters in written words systematically map onto the sounds they hear in spoken language. When having acquired this understanding and having learned the sounds of letters in the alphabet, young learners can then move to the next phase. In this particular one, i.e. the partial alphabetic phase, children do not have complete knowledge of the alphabetic system and thus retain having difficulty with some letter-sound association. When children are able to construct full associations between letters and sounds within pronunciations, they move to the full alphabetic phase. Within this phase, grapheme-phoneme relations in words are kept as larger units in memory. As for the consolidated alphabetic phase, Ehri (2005) presented a discussion of the advantages of this process for reducing memory load. For example, in the consolidated phase, the word 'chest' might be processed only as two units 'ch' '-est' compared with four units (ch, e, s, t) in the full alphabetic phase.

The present paper chose Ehri's (2005) phases of word recognition development since it tackles emergent readers' acquisition of word recognition. The model only refers to emergent readers who are at the word level of text (Beecher, 2011; Ebert, 2009), featuring as a deep detailed model of early word recognition as well (Ebert, 2009).

\section{Research Method}

Cohen, Manion, and Morrison (2007) affirmed that the research questions and objectives of the study determine the design of any research. Therefore, the current research used qualitative research method to explore the impact of the phonemic awareness skill on emergent readers' word recognition

\subsection{Sample of the study}

The sample in this research was 7 Jordanian EFL emergent readers from Jerash Basic State School for Boys. In the semi-structured interview, a purposive/ homogeneous sampling was used by the researcher (Creswell, 2012). As for this particular sampling, the researcher 
The Influence of Phonemic Awareness Instruction on EFL Emergent Readers' Word Recognition, Mohammad Husam Alhumsi

randomly selected 7 students from the school mentioned above since they had the same experience as emergent readers according to their teachers (Creswell, 2012).

\subsection{Instrumentation}

The instrument used in this study was semi-structured interviews of the emergent students adapted from Thajakan and Sucaromana (2014). Seven respondents participated in the interview questions. Those participants were male emergent readers. They were all Arabic native speakers aged seven years on average. They showed their willingness in participating in the interview. The semi-structured interview was conducted in Arabic since the study involved EFL emergent readers. This could help the researcher get more accurate data if the students were interviewed in a language fully understood by them (Thajakan \& Sucaromana, 2014). In addition, to ensure the quality of the semi-structured interview process, the researcher followed Brantlinger's et al. (2005) quality indicator guidelines used for qualitative studies. The guidelines used for the semi-structured interview include five items such as selecting appropriate individual participants, clear interview questions, using adequate mechanisms to record and transcribe the interviews, participants are represented sensitively representing sensitive and fair report concerning the individual participants, and using sound measures to ensure confidentiality (Brantlinger et al., 2005).

\subsection{Research Procedure}

It should be noted that seven participants were randomly selected to take part in a semi-structured interview. The interview consisted of six open-ended questions to identify the students' views on the impact of learning phonemic awareness skill on word recognition. During the interview, probing questions are used to gather as much information as possible and the interviewer used them as a means of follow-up (Turner, 2010).

\subsection{Data Analysis}

Walliman (2011) clearly showed the importance of analysing data in order to gauge, make comparisons, forecast, examine relationships, test hypotheses, explore, control and explain, construct concepts and theories. In this paper, a qualitative data analysis was conducted with the data gained from the semi-structured interview. All the information from the interviewed was analyzed using content analysis. The data was thus classified into positive or negative views. In short, the researcher analysed the responses of EFL emergent readers into positive or negative views qualitatively since the purpose of this qualitative study was to explore the impact of the phonemic awareness skill on word recognition among Jordanian EFL emergent readers. A video recording was used to record the interview in order to facilitate the review process.

\section{Results and Discussion}

The analysis of this qualitative data regarding the research question was conducted with the data obtained from the semi-structured interviews. Six questions have been posed. All the information from the interview was analyzed using positive and negative views in order to ascertain the EFL emergent readers' views regarding the impact of learning phonemic awareness skill on word recognition. Thus, the data was classified into positive or negative views (Thajakan \& Sucaromana, 2014). The findings from the semi-structured interviews are presented as follows: 


\subsection{Q1. Emergent Readers' Responses towards the Preferred Subject at School}

As an introductory question, students were asked to have their responses regarding the subject preferred at school. There were varying answers when the participants were asked about their favourite subject. It has been found that the majority of them preferred the subject of English language. When asked of the favourable subject liked at school, the participants reported that they like the subject of English language. This is evident from one of the participant's response (Student 2):

\section{"The English Language"}

This shows a positive tendency towards the subject of English. Thus, the first question works as a preliminary to the other questions.

\section{2 Q2. Emergent Readers' Responses of How to Read Words}

The second question dealt with the way the interviewed participants used to read words. It has been found that four participants claimed that they use the strategy of phonemic awareness when they want to read English words. Their responses they gave in support of their answers are shown below:

Student 1 replied when asked the way he read the word "goal":

"We spell the first letter then we read the $/ \mathrm{g} /$ the first sound"

As for Student 2, he confidently replied:

"We divide the word into its sounds then we read it".

Similarly, Student 3 had the same idea and he added that

"We divide the word into its sounds, blend the sounds and then we read it"

Student 5 just uttered the sounds of the word being asked about. Student 5's reply was:

$$
\text { "/g/, /O/, /l/" }
$$

On the other hand, only three participants claimed that they spell the word in order to read it. For example, when the interviewer asked (Student 4) about the way he read the word "goal", he replied:

"We divide the word. Then we combine the letters"

In the same thread, the response of Student 6 was:

"We spell the word"

The interviewer asked Student 6 what you do next. He replied:

"We put the letters together"

In addition, the response of Student 7 when asked about the way he read the word "goal" was:

"We spell then we read. I spell the word through dividing it".

This indicates that more than half of the interviewed participants show positive responses towards using phonemic awareness skill in order to read words. However, a few interviewees prefer to use spelling in order to read.

\subsection{Q3. Emergent Readers' Responses towards How to Recognize a Word}

As stated in the third question, the interviewed participants were asked how they recognize an English word. Although the words were read correctly among students, the interviewed participants demonstrated a considerable inclination of reading words through the first letter and sound relationship. It is interesting to note that the majority of the participants stated that they recognize the words from the first sound or the first letter. For 
The Influence of Phonemic Awareness Instruction on EFL Emergent Readers' Word Recognition, Mohammad Husam Alhumsi

example, when the interviewer asked Student 3 the way he recognized the word "man", he replied

$$
\text { "Because of } / \mathrm{m} / \text {, the first sound" }
$$

Similarly, when asked the way he recognized the word "man", the response of Student 2 was:

"We divide the word into its sounds, and then we read the first sound / $/ \mathrm{m} /$ "

Moreover, Student 5's reply was:

"I know the word from the first " $m$ ", " $a$ ", and " $n$ ". Then, we combine these sounds together"

Consequently, the first sounds or letters of words were the cues of their successful reading. Another participant (Student 1) claimed that he can blend the sounds within words. His response was:

"I spell the word, the first letter " $m$ " and the last letter " $n$ ". I spell it and I combine the sounds together"

In addition, when asked the way he recognized the word "man", Student 7's reply was:

"Because of the letter " $m$ "'"

On the other hand, Student 6 claimed that he can recognize the words from the pronunciation and the English letters. His response was:

"Because of the pronunciation and the English letters: " $m$ ", " $a$ ", " $n$ "

Thus, most of the participants show positive responses towards identifying the word on the basis of the first sound or the first letter.

\subsection{Q4. Participants' Responses towards the Sound /n/}

With respect to the fourth question, the participants were asked about the sound of " $n$ ". most of the interviewed participants greatly identify the sound /n/. They showed the sound /n/ without hesitation. For example, Student 1 showed great confidence when producing the sound $/ \mathrm{n} /$. When asked to identify the sound of $/ \mathrm{n} /$, he replied:

"nnnn"

The other participants showed the same confidence. However, Student 7 offered the word "man" without referring to the required sound. He replied: (stretching the sound)

"mmm aaa nnn"

As a result, this indicates that most of the participants have positive responses towards identifying the sound /n/. Further, they show considerable confidence in their response.

\subsection{Q5. Emergent Readers' Responses towards the Final Sound in the Word "Cake"}

The fifth question dealt with the interviewees' responses towards identifying the final sound in the word "cake". It has been found that the majority of the participant students identify the final sound in the word "cake". They also showed great confidence in their response. For example, when asked to identify the final sound in the word "cake", the response of Student 4 was: (stretching the sound).

"kkk"

Similarly, the other students showed a remarkable confidence in identifying the final sound in the word "cake". Despite of the correct responses towards identifying the final sound in the word "cake", only two of the interviewed participants produced incorrect answers. These two participants could not identify the final sound. Instead, they identify the 
last letter which is the letter "e". For example, Student 5 and Student 7 gave incorrect answers when identifying the final sound in the word "cake" Student 5's was:

"eee"

To sum up, this clarifies that the majority of the interviewed participants show positive responses towards identifying the final sound $/ \mathrm{k} /$. On the contrary, few participants show negative responses in identifying the sound / $/$.

\subsection{Q6. Emergent Readers' Views towards the Skill of Phonemic Awareness}

As for the sixth question, the participants were asked about their views towards the skill of phonemic awareness. There was general consensus about the issue of phonemic awareness skill. All participants showed positive views regarding the skill of phonemic awareness. They claimed that this skill helped them read words as stated in all their responses. Furthermore, they had been asked whether phonemic awareness is a good skill. They contended that phonemic awareness is a good skill. For example, the response of Student 1 was:

"Yes, it is a good skill and it helps us"

When the interviewer asked the same student about the benefit of this skill if we for example divide the word "man", he replied:

"We combine the sounds / $\mathrm{mmm}$ aaa $\mathrm{nnn} /$ "

The interviewer also asked Student 1 whether this skill helps us in reading. Student 1's reply was:

"Yes, it helps us read words"

In the same thread, Student 2 and Student 4 showed high confidence in relation to their responses. For instance, when asked about his view of phonemic awareness skill, the response of Student 4 was:

\section{"Good". "It helps us read words"}

Additionally, when the interviewer asked whether the skill of phonemic awareness helps us in reading, Student 3, Student 5, Student 6, and Student 7 replied:

"It helps us in reading".

As a result, this indicates that all participants have positive perceptions towards the skill of phonemic awareness in conjunction with their responses.

Thus, general consensus was noticeably achieved with the issue of the impact of the skill of phonemic awareness on word recognition among Jordanian EFL emergent readers. This result indicates that positive impact occurred between the skill of phonemic awareness and word recognition. To sum up, qualitative data showed that Jordanian EFL emergent readers support positive views in conjunction with the learning of the skill of phonemic awareness and word recognition.

With reference to the discussion of the results, the semi-structured interview revealed the ways how students perceive the questions provided to them. In the first introductory question with respect to the subject preferred at school, most of the interviewees have tendencies towards the subject of the English language compared to other subjects. This shows they like English language classes. In relation to the second question, it tackles the interviewees' views regarding the way they read English words. Most of them claimed they employ the phonemic awareness strategy when reading English words. Many of the interviewees claimed that the first sounds were the cues for their successful reading. They showed a great inclination of recognizing the sounds of the words by making letter- sound association. This means there is a remarkable indication for the lack of 
knowledge or misunderstanding of phonic and phonemic awareness. This result goes in line with the study conducted by Bos et al. (2001). The fourth question involves whether beginning readers can identify the sound $/ \mathrm{n} /$. It is important to indicate that large number of interviewed participants identify the sound /n/. Additionally, concerning the fifth question, most of interviewed participants successfully identify the final sound in the word "cake". They show no hesitation while uttering the final sound $(/ \mathrm{k} /)$ of that particular word "cake". In the sixth question of the interview, the participants gave their views regarding the issue of the skill of phonemic awareness.

Overall, based on these results, one can conclude that the interviewed participants had positive views concerning the skill of phonemic awareness. It is important to indicate that these outcomes are similar to those discussed in the research studies existed in the literature such as the study of Gyovai et al. (2009) in which the most effective level that predicts reading as well as spelling skills in the beginning years of school is the level of phonemic awareness. Additionally, the findings of the current study are also in accordance with the study of Castiglioni-Spalten and Ehri (2003) in which children already recognized the letters' names that described the sounds being manipulated.

\section{Conclusion}

The current study includes the following conclusions: First, the phonemic awareness skill is relevant to the development of word recognition of Jordanian EFL emergent readers. Second, the explicit phonemic awareness instruction is of paramount importance to this development. Third, the participants enjoy the favourable uses of phonemic awareness skill and this was done through their investigation using qualitative methods represented by the semi-structured interview.

Based on the findings of the qualitative design, the researcher recommends that more research works should be triggered to investigate the effectiveness of various training instructions on students' performance in other English phonological awareness skills on the word level such as rhyming, syllable segmentation and onset-rime, blending and segmentation (Chard \& Dickson, 1999). Given the studies that attest the effectiveness of phonological awareness instructions, particularly phonemic awareness, this may convince English learners, authors of school formal books, educator trainers, and curriculum designers to pay attention to the benefits and advantages of such instructions as well as incorporating these instructions within their classes, school formal books, and curricula. Moreover, the current study mainly used qualitative method. However, future studies should be conducted to have more focus on quantitative research instrument to get a clearer image in the educational field relating to other phonological awareness skills.

It is good to note that phonological awareness can be taught and learnt; this supports the view advocated by some scholars (e.g. Ehri, 2005; Snow et al. 1998; Ball and Blachman 1991). Another implication is pedagogical proposing that explicit phonological awareness instruction, particularly phonemic awareness, can be integrated in Jordanian curricula with respect to Jordanian EFL children from the first grade as there has been a remarkable progress in English word recognition ability of emergent readers. Finally, this study was limited to the population from which the sample was drawn. It dealt with EFL emergent readers who are in the first grade in basic state schools in Jerash, Jordan. 


\section{Acknowledgements}

The researcher is very thankful to the school administration and the pupils who participated in this study.

\section{References}

Aarnoutse, C., Van Leeuwe, J., \& Verhoeven, L. (2005). Early literacy from a longitudinal perspective. Educational Research and Evaluation, 11(3), 253-275.

Adams, M. (1994). Beginning to read: Thinking and learning about print. Cambridge, MA: MIT Press.

Alhumsi, M. \& Affendi, A. (2014). Beginning readers have no prior experience with sound segmentation. Journal of Education and Practice, 5 (11), 32-41.

Alhumsi, M. \& Affendi, A. (2016). The relationship between phonemic segmentation skill and EFL word recognition- A review of literature. International Journal of Linguistics, $8(2), 31-46$.

Al Otaiba, S., Kosanovich, M., \& Torgesen, J. (2012). Assessment and instruction in phonemic awareness and word recognition skills. In A. G. Kamhi \& H. W. Catts (Eds.), Language and reading disabilities (3rd ed., pp. 112-145). Upper Saddle River, NJ: Pearson Education Inc.

Al-Shaboul, Y., Assasfeh, S., Alshboul, S., \& Almomani, H., (2013). Are Jordanian students phonemically aware? : A descriptive study. Journal of Educational \& Psychological Sciences, 14 (2), 37-53.

Anthony, J. \& Lonigan, C. (2004). The nature of phonological awareness: converging evidence from four studies of preschool and early grade school children. Journal of Educational Psychology, 96 (1), 43-55.

Anthony, J., Williams, J., McDonald, R., \& Francis, D. (2007). Phonological processing and emergent literacy in younger and older preschool children. Annals of Dyslexia, 57(2), 113-137.

Archibald, L. \& Gathercole, S. (2007). Nonword repetition in specific language impairment: More than a phonological short-term memory deficit. Psychonomic Bulletin \& Review, 14 (5), 919-924.

Baddeley, A. (2007). Working memory, thought and action. New York: Oxford University Press

Ball, E. \& Blachman, B. (1991). Does phoneme awareness training in kindergarten make a difference in early word recognition and developmental spelling? Reading Research Quarterly, 26(1), 49-66.

Beech, J. (2005). Ehri's model of phases of learning to read: a brief critique. Journal of Research in Reading, 28 (1), 50-58.

Beecher, C. (2011). A latent growth curve analysis of reading achievement for an at-risk population. (Doctoral Dissertation). Washington State University, USA.

Brantlinger, E., Jimenez, R., Klingner, J., Pugach, M., \& Richardson, V. (2005). Qualitative studies in special education. Exceptional children, 71(2), 195-207.

Bos, C., Mather, N., Dickson, S., Podhajski, B., \& Chard, D. (2001). Perceptions and knowledge of preservice and inservice educators about early reading instruction. Annals of Dyslexia, 51, 97-120.

Castiglioni-Spalten, M. \& Ehri, L. (2003). Phonemic awareness instruction: Contribution of articulatory segmentation to novice beginners' reading and writing. Scientific Studies of Reading, 7(1), 25-52. 
The Influence of Phonemic Awareness Instruction on EFL Emergent Readers' Word Recognition, Mohammad Husam Alhumsi

Castles, A., Rastle, K., \& Nation, K. (2018). Ending the reading wars: Reading acquisition from novice to expert. Psychological Science in the Public Interest, 19(1), 5-51.

Chapman, M. (2003) Phonemic awareness: Clarifying what we know. Literacy Teaching and Learning, 7 (1 \& 2), 91-114.

Chard, D., \& Dickson, S. (1999). Phonological awareness: Instructional and assessment guidelines. Intervention in School and Clinic, 34(5), 261-270.

Cohen, L., Manion, L., \& Morrison, K. (2007). Research methods in education (6 ${ }^{\text {th }}$ ed.). Routledge. NY

Creswell, J. (2012). Educational research: Planning, conducting, and evaluating quantitative and qualitative research (4th ed.). Boston, MA: Pearson.

Dehaene, S. \& Naccache, L. (2001). Towards a cognitive neuroscience of consciousness: basic evidence and a workspace framework. Cognition, 79 (1), 1-37.

Ebert, A. (2009). Developmental spelling and word recognition: A validation of Ehri's model of word recognition development. (Doctoral dissertation) The University of Virginia, USA.

Ehri, L. (2005). Development of sight word reading: Phases and findings. In M. J. Snowling \& C. Hulme (Eds.), The science of reading: A handbook (pp. 135-154). Malden, MA: Blackwell.

Ehri, L. (2014) Orthographic mapping in the acquisition of sight word reading, spelling memory, and vocabulary learning. Scientific Studies of Reading, 18(1), 5-21.

Ehri, L., Nunes, S., Willows, D., Schuster, B., Yaghoub-Zadeh, Z. \& Shanahan, T. (2001). Phonemic awareness instruction helps children learn to read: Evidence from the national reading panel panel's meta -analysis. Reading Research Quarterly, 36(3), 250-287.

Fender, M. (2003). English word recognition and word integration skills of native Arabic and Japanese- speaking learners of English as a second language. Applied Psycholinguistics, 24(2), 289-315.

Foy, J., \& Mann, V. (2006). Changes in letter sound knowledge are associated with development of phonological awareness in pre-school children. Journal of Research in Reading, 29(2), 143-161.

Fraenkel, J., \& Wallen, N. (2009). How to design and evaluate research in education, 7th ed. New York, NY: McGraw Hill.

Ganie, R., Maulana, W., \& Rangkuti, R. (2019). ERRORS IN PRONOUNCING ENGLISH PHONEMES: A PRAAT ANALYSIS. Language Literacy: Journal of Linguistics, Literature, and Language Teaching, 3(1), 49-63.

Good, R., Simmons, D., \& Smith, S. (1998). Effective academic interventions in the United States: Evaluating and enhancing the acquisition of early reading skills. School psychology review. 27 (1), 45-56.

Gove, A. \& Cvelich, P. (2010). Early reading: Igniting education for All. A report by the early grade learning community of practice. Research Triangle Park, NC: Research Triangle Institute.

Gray, A., \& McCutchen, D. (2006). Young readers' use of phonological information: phonological awareness, memory, and comprehension. Journal of Learning Disabilities, 39(4), 325-333.

Griffith, P. \& Olson, M. (1992). Phonemic awareness helps beginning readers break the code. The Reading Teacher, 45(7), 516-523. 
Gyovai, L., Cartledge, G., Kourea, L., Yurick, A., \& Gibson, L. (2009). Early reading intervention: Responding to the learning needs of young at-risk English language learners. Learning Disability Quarterly, 32(3), 143-162.

International Reading Association. (1999). Using multiple methods of beginning reading instruction: A position statement of the International Reading Association. Newark, Delaware.

Kern, M., \& Friedman, H. (2008). Early educational milestones as predictors of lifelong academic achievement, midlife adjustment, and longevity. Journal of Applied Developmental Psychology, 30(4), 419-430.

Kim, D., Kim, W., \& Lee, K. (2007). The relationship between phonological awareness and early reading for first grade Korean language learners with reading difficulties. Asia Pacific Education Review, 8(3), 426-434.

Kucukoglu, H. (2013). Improving reading skills through effective reading strategies. ProcediaSocial and Behavioral Sciences, 70, $709-714$.

Lane, H., Pullen, P., Eisele, M., \& Jordan, L. (2002). Preventing reading failure: Phonological awareness assessment and instruction. Preventing School Failure, 46(3), 101-110.

Lonigan, C., Schatschneider, C., \& Westberg, L. (2008). Results of the national early literacy panel research synthesis: Identification of children's skills and abilities linked to later outcomes in reading, writing, and spelling. In Developing early literacy: Report of the National Early Literacy Panel (pp. 55-106). Washington, DC: National Institute for Literacy.

Manning, M. (2005). Phonemic awareness: As kids learn how to read and write, their phonemic awareness will gradually develop. Teaching $K-8,36$ (3), 68-69.

Nag S., Chiat S., Torgerson C., Snowling M. (2014) Literacy, foundation learning and assessment in developing countries: Final Report. Education rigorous literature review. Department for International Development.

National Reading Panel. (2000). Report of the National Reading Panel: Teaching children to read. An evidence-based assessment of the scientific research literature on reading and its implications for reading instruction. Retrieved May 20, 2015 from https://www.nichd.nih.gov/publications/pubs/nrp/pages/smallbook.aspx

Nation, K. \& Hulme, C. (1997). Phonemic segmentation, not onset-rime segmentation, predicts early reading and spelling skills. Reading Research Quarterly, 32(2), 154-167.

Perfetti, C. \& Marron, M. (1998). Learning to read: Literacy acquisition by children and adults. In D.A. Wagner (Ed.). Advances in adult literacy research and development. Hampton Press.

Schuele, M. \& Boudreau, D. (2008). Phonological awareness intervention: Beyond the basics. Language, Speech, and Hearing Services in Schools, 39 (1), 3-20.

Senechal, M. \& LeFevre, J. (2002). Parental involvement in the development of children's reading skills: A five-year longitudinal study. Child Development, 73(2), 445-460.

Shankweiler, D. \& Fowler, A. (2004). Questions people ask about the role of phonological processes in learning to read. Reading and Writing: An Interdisciplinary Journal 17(5), 483-515.

Snow, C., Burns, S \& Griffin, P (eds.). (1998). Preventing reading difficulties in young children. Washington, DC: National Academy Press.

Stanovich, K. (1986). Matthew effects in reading: Some consequences of individual differences in the acquisition of literacy. Reading Research Quarterly, 21(4), 360-407. 
Suggate, S., Schaughency, E., \& Reese, E. (2013). Children learning to read later catch up to children reading earlier. Early Childhood Research Quarterly, 28(1), 33- 48.

Torgesen, J., Alexander, A., Wagner, R., Rashotte, C., Voeller, K., \& Conway, T. (2001). Intensive remedial instruction for children with severe reading disabilities: Immediate and long-term outcomes from two instructional approaches. Journal of Learning Disabilities, 34 (1), 33-58, 78.

Tunmer, W. \& Nesdale, A. (1985). Phonemic segmentation skill and beginning reading. Journal of educational Psychology, 77(4), 417.

Vaughn, S., \& Linan-Thompson, S. (2004). Research-based methods of reading instruction: Grades K-3. Alexandria, VA: Association for Supervision and Curriculum Development.

Walliman, N. (2011). Research methods: The basics. NY. Routledge.

Walsh, R. (2009). Word games: the importance of defining phonemic awareness for professional discourse. Australian Journal of Language and Literacy, 32(3) 211-225.

Westwood, P. (2001). Reading and Learning Difficulties. Victoria: ACER Press.

Whitehurst, G. \& Lonigan, C. (1998). Child development and emergent literacy. Child Development, 69(3), 848-872.

Yeh, S. (2003). An evaluation of two approaches for teaching phonemic awareness to children in head start. Early Childhood Research Quarterly, 18(4), 513-529.

Yeh, S., \& Connell, D. (2008). Effects of rhyming, vocabulary, and phonemic awareness instruction on phonemic awareness. Journal of Research in Reading, 31 (2), 243-256.

Yopp, H. (1992). Developing phonemic awareness in young children. The Reading Teacher, 45(9), 696-703.

Yopp, H. \& Yopp, R. (2000). Supporting phonemic awareness development in the classroom. The Reading Teacher, 54(2), 130-143.

Yopp, H. \& Yopp, R. (2009). Phonological awareness is child's play! YC Young Children, 64(1), 1-9. 